\title{
ANALYSIS OF PULSED INFRARED THERMAL NON-DESTRUCTIVE TESTING ON CARBON FIBER REINFORCED POLYMER
}

\author{
Peiqi Jiang, Xingwang Guo \\ School of Mechanical Engineering and Automation, Beihang University, Xueyuan Road No.37, \\ Beijing 100191, PR China
}

\begin{abstract}
Carbon fiber reinforced polymer (CFRP) is widely used in aviation and aerospace manufacturing due to its high specific strength, high specific modulus and high designability. In the production process of CFRP, some defects can't be completely avoided. This paper focuses on the numerical simulation of pulsed infrared thermal non-destructive testing of delamination defects in CFRP. A two-dimensional model was established in the finite element analysis (FEA) to study the effect of defect size and defect depth on the defect informative parameters. Afterwards, an experiment was conducted to verify the results of numerical simulation and to find the detection limits of depth and size of delamination defects under the normal heating conditions.
\end{abstract}

KEYWORDS: carbon fiber reinforced polymer, pulsed infrared thermography, delamination defects, finite element analysis

\section{INTRODUCTION}

CFRP is a composite material with resin as matrix and carbon fiber as reinforcement, which has been developed in the middle of 1960s. It is a highly promising material in aeronautical and aerospace industries. The CFRP components are superior to other materials mainly due to its high specific strength, high specific modulus, high designability, high damping and good corrosive resistance properties. ${ }^{[1,2]}$

As a new material, CFRP has been widely used, but in the production process, some defects like delamination, voids and inclusions can't be completely avoided due to the instability of the process.

This paper will use the finite element method to analyze the pulsed infrared thermography of CFRP, aimed at finding the influence law of the defect depth and size on the defect informative parameters.

\section{FINITE ELEMENT ANALYSIS}

\subsection{NUMERICAL MODELING}

During the numerical simulation, considering the simulation efficiency and the neglect of mutual influence between defects under the real condition, each defect was modeled separately. A three-dimensional model was used to describe the heat conduction of a circular lamination 
defect in CFRP, as shown in Fig. 1(a), where the defect area is filled with air.

Because of the axial symmetry of the three-dimensional model, it could be converted into a two-dimensional model, as shown in Fig. 1(b), where $L$ denotes the model radius, $H$ denotes the model thickness, $l$ denotes the defect radius, $\delta$ denotes the defect thickness, $h$ denotes distance from the defect to the inspection surface, point $\mathrm{D}$ and $\mathrm{N}$ denote the center of the defect and non-defect areas on the inspection surface respectively.

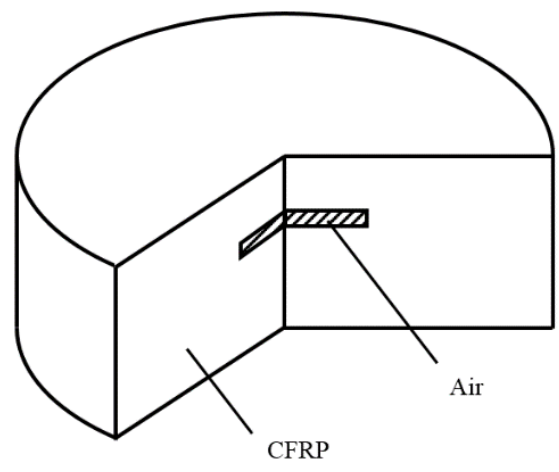

(a) 3D simulation model

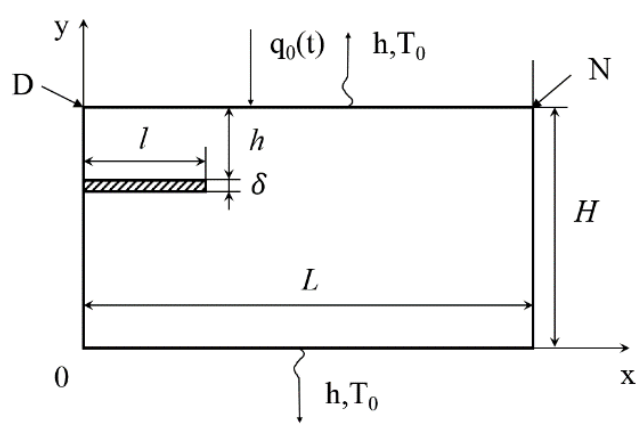

(b) 2D simulation model

Fig. 1 Numerical Simulation models

The thermal properties of materials are listed in Table 1.

Table 1 Thermal properties of materials

\begin{tabular}{|c|c|c|c|}
\hline Material & $\begin{array}{r}\text { density } \rho \\
/ \text { kg m }^{-3}\end{array}$ & $\begin{array}{l}\text { specific heat c } \\
\qquad / \mathrm{J} \mathrm{kg}^{-1} \mathrm{~K}^{-1}\end{array}$ & $\begin{array}{l}\text { Thermal conductivity } \mathbf{k} \\
\qquad / \mathbf{W ~ m}^{-1} \mathbf{k}^{-1}\end{array}$ \\
\hline & & & X-direction 2.16 \\
\hline \multirow[t]{2}{*}{ CFRP } & 1900 & 677 & Y-direction 1.8 \\
\hline & & & Z-direction 2.16 \\
\hline Air & 1.205 & 1005 & 0.0259 \\
\hline
\end{tabular}

\subsection{SIMULATION RESULTS}

The numerical simulation was performed by finite element method using the software ANSYS TM. The initial temperature was set to $T_{0}=0^{\circ} \mathrm{C}$. In heating stage, the heat flux loaded on the surface was set to $q_{0}=2.0 \times 10^{6} \mathrm{~W} / \mathrm{m}^{2}$ with a heating duration $\mathrm{t}_{\mathrm{h}}=0.01 \mathrm{~s}$. In radiating stage, the convection heat transfer occurring on the top and bottom surfaces of the model was considered with a heat convection coefficient $h=10 \mathrm{~W} /\left(\mathrm{m}^{2} \mathrm{~K}\right)$, and the side surface of the model was taken to be adiabatic. The radiating time was set to $t_{\mathrm{r}}=20 \mathrm{~s}$.

Set the structure parameters as the followings: $L=20 \mathrm{~mm}, H=10 \mathrm{~mm}, l=2 \mathrm{~mm}, h=1 \mathrm{~mm}$, $\delta=0.2 \mathrm{~mm}$. The simulation results was shown in Fig. 2 . 


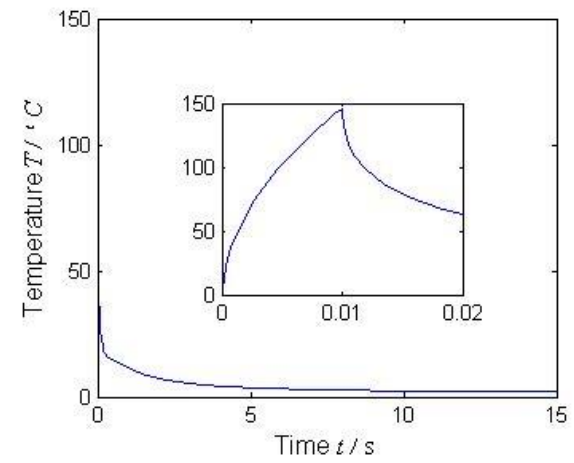

(a) Temperature evolution of defect point $\mathrm{D}$

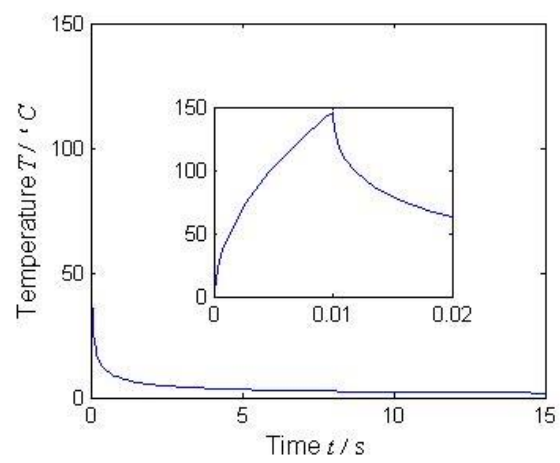

(b) Temperature evolution of non-defect point $\mathrm{N}$

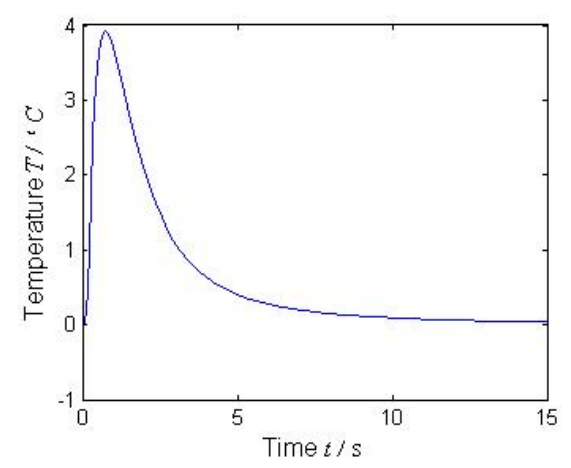

(c)Temperature difference between defect point $\mathrm{D}$ and non-defect point $\mathrm{N}$

Fig. 2 Numerical simulation results

In Fig. $2(\mathrm{c})$, the maximum temperature difference $\left(\Delta T_{m}=3.92^{\circ} \mathrm{C}\right)$ occurs at time $t_{m}=$ $0.75 s$ that can be seen as the best time for defect identification.

\subsection{EFFECT OF DEFECT SIZE ON DETECTION RESULTS}

The effect of defect size on the defect informative parameters was studied by numerical simulation for different sizes of defect.

\subsection{EFFECT OF DEFECT DEPTH ON DETECTION RESULTS}

The effect of defect depth on the defect informative parameters was studied by numerical simulation for different depths of defect.

\section{EXPERIMENT}

Experiments was carried out with samples containing artificial defects and natural defects to validate the simulation results.

\section{CONCLUSIONS}

The guideline for the delamination detection of carbon fiber reinforced polymers by using pulsed infrared thermography will be obtained from the following aspects:

(1) the effect of defect size on the detectability;

(2) the effect of defect depth on detectability;

(3) the detection limits of depth and size of delamination defects under a normal heating conditions. 
http://dx.doi.org/10.21611/qirt.2017.025

\section{REFERENCES}

[1]S.R. Karnika, V.N. Gaitondeb, et al. Delamination analysis in high speed drilling of carbon fiber reinforced plastics (CFRP) using artificial neural network model[J]. Materials \& Design, 2008, 29(9): 1768-1776.

[2]S. Takeda, Y. Okabe, N. Takeda. Delamination detection in CFRP laminates with embedded small-diameter fiber Bragg grating sensors[J]. Composites Part A, 2002, 33: 971-980. 